\title{
La figuración del frente costero para la ciudad de Posadas*
}

\author{
María del Rosario Millán \\ Universidad Nacional de Misiones, Posadas, Argentina. \\ Email: mariamillan@conicet.gov.ar
}

Resumen: Este artículo aborda el proceso de figuración del nuevo frente costero para la ciudad de Posadas, Misiones, Argentina, considerando la construcción discursiva del objeto costa en un corte diacrónico del corpus compuesto por planes y proyecto de intervención urbanística. Entiendo por figuración el haz de representaciones e imágenes proyectadas del espacio costero configurado en un escenario particular: la elevación de las aguas del río Paraná por la formación del embalse de la represa Yacyretá. Se toman en consideración diversos aspectos vinculados con la formación discursiva sobre el desarrollo, movilizados para la implementación de políticas urbanas, que ponen en escena el problema de la articulación entre el plano discursivo y el plano físico de las transformaciones urbanas. Así también se describe el dispositivo enunciativo del proceso de figuración, la posición de sujeto predominante y sus efectos de sentido.

Palabras clave: discurso, costa, formación discursiva sobre el desarrollo, Represa de Yacyretá.

\section{The figuration of a new front coast for the city of Posadas}

Abstract: This paper tackles the figuration process of the New Coast Front of Posadas, Misiones, Argentina, considering semiotic construction of the coast as a discursive object, using a diachronic corpus that gathers urban plans and projects. Figuration is an axe of projected representations and images for the coast bearing in mind the water reservoir on Paraná River formed by Yacyretá dam. Diverse aspects linked to development's discursive formation are treated in this article, mobilized to implement urban policies that put on scene the problem of articulation between discursive and physics planes of transformation. Besides it is described enunciation device of the figuration process, predominant subject position and its effects of sense. dam.

Key words: discourse; coast; development discursive formation; Yacyretá

\section{A figuração da nova orla para a cidade de Posadas}

Resumo: Este artigo discute o processo de representação da nova orla da cidade de Posadas, Misiones, Argentina, considerando a construção discursiva da costa assunto em um corpus diacrônico dos planos do projeto e planejamento de intervenção. Entenda como figuração o feixe de representações e as imagens projetadas da zona costeira situado num cenário particular: a subida das águas do rio Paraná, pela formação do reservatório da represa de Yacyretá. São levados em consideração aspectos diversos relacionados com a formação discursiva de 
desenvolvimento, mobilizados para a execução das políticas urbanas, que coloca em cena o problema da relação entre o nível do discurso eo plano físico da transformação urbana. Este também descreve o dispositivo do processo de configuração, a posição do sujeto dominante e seus efeitos de sentido.

Palavras-chave: discurso, costa, formação do discurso do desenvolvimento, Represa de Yacyretá.

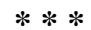

\section{Introducción}

Posadas, capital de la Provincia de Misiones, Argentina, ubicada en la frontera con Encarnación, Paraguay, es una ciudad intermedia, integra unas de las regiones más pobres y atrasadas del país (Posadas es la tercera ciudad más pobre de la Argentina según datos de la Encuesta Permanente de Hogares, primer semestre 2010). Vive desde hace varios años profundas transformaciones socioeconómicas que están modificando su aspecto urbano. Algunos autores consideran que ese proceso es parte de la conformación de un nuevo orden urbano ligado con: 1) El impacto de la represa Yacyretá ${ }^{1}$, un proyecto de gran escala entendido como una forma particular de producción estructuralmente conectada con la expansión de sistemas económicos y políticos; escenario privilegiado para el estudio de los procesos de articulación de grupos de poder que incluyen intereses locales, nacionales e internacionales (Lins Ribeiro, 1999). 2) La reestructuración territorial de los estados nacionales y la configuración de regiones económicas extensas como el MERCOSUR (Barreto, 2004). 3) Un nuevo patrón de urbanización que se caracteriza por el mayor crecimiento relativo de las ciudades intermedias (Barreto, 2002). 4) Las acciones de los gobiernos provincial y municipal que diseñan e implementan estrategias para ubicar a Posadas como destino turístico en el circuito internacional ${ }^{2}$. La construcción de la Avenida Costanera (vía de circulación - recreación para la ciudad y obra de contención del lago que se formará por la represa Yacyretá) y la estructuración de un nicho territorial en la costa norte -noreste para los sectores más adinerados, son manifestaciones de la particularidad local que adquiere ese nuevo orden urbano.

Bajo estas condiciones Posadas experimenta un acelerado proceso de reurbanización cuyo patrón de organización se rige por el eje dentro/ fuera, que mediante un movimiento centrífugo expulsa a los pobres urbanos de las zonas más céntricas de la ciudad cercanas a la costa.

La reurbanización también se concreta con la remodelación del espacio urbano costero y céntrico, en particular con intervenciones que apuntan a la creación de espacio público orientado hacia actividades comerciales recreativas. Este proceso puede ser sintetizado del siguiente modo: 1) Selección de zonas por remodelar y recuperar, en función del nuevo paradigma de las políticas urbanísticas estatales. Apropiación del suelo que posibilita negocios inmobiliarios, comerciales y de recreación en zonas 
generalmente costeras, sometidas a procesos de estetización y embellecimiento (Motto, 2005). 2) Erradicación de la población (pobres urbanos) que ocupaba esos espacios. 3) Ejecución pública-privada de los proyectos urbanísticos de remodelación. 4) Transformación de esos espacios en urbanizaciones de/para sectores con poder de consumo (“zona recreativa”, apta para el mercado de la diversión y para el turismo recreativo). 5) Concentración y aumento de la rentabilidad urbana, principalmente en manos de sectores inmobiliarios y de la construcción (Maidana, Millán, 2009: 124-125).

Estos procesos de producción espacial pueden ser analizados desde diversas perspectivas teóricas. La priorizada en este artículo es semiótica discursiva y apunta a considerar el eje discursivo de las políticas públicas de intervención urbana a partir de la revisión de los planes y proyectos diseñados para la ciudad, particularmente sobre el espacio costero. El objeto, entonces, se circunscribe al estudio de "Posadas proyectada", un tipo particular de práctica que produce representaciones espaciales determinadas.

\section{Espacios de representación}

Mi atención se focalizó en el dominio de los espacios de representación que como toda práctica de representación y producción espacial es siempre una práctica de poder ligada a relaciones sociales específicas en un momento determinado. Es decir, un trabajo ideológico semiótico por el cual ciertos sectores de la sociedad -hacedores de ciudad con mayores ventajas que otros- buscan legitimar sus acciones e intereses. Dicho trabajo es considerado un ejercicio de imaginación urbanística, dimensión política técnica producida en y por el discurso urbanístico acerca de cómo debe ser la ciudad (Gorelik, 2004), que mediante la aplicación de un método proyectual -solución aparente de la tensión entre racionalidad e imaginación, en el juego entre lo no construido, lo preconstruido y lo construido-, instituye y legitima modelos de ciudad (ciudades modelos).

De allí el interés por indagar en el proceso discursivo ${ }^{3}$ por el cual la imaginación urbanística fue proyectando la costa de la ciudad, creando representaciones que ya forman parte del imaginario urbano, entendido como sistema de imágenes y representaciones simbólicas referenciadas en el espacio de la ciudad (Bekinschtein, Caride, Gravano, 2000: 91) .

El supuesto de partida es que para la transformación de la costa posadeña, particularmente con la proyección de la Avenida Costanera, la dimensión simbólico ideológica del "espacio público moderno"4 fue un elemento clave para minimizar y ocular el impacto de las políticas neoliberales sobre el territorio (Barreto, 2004). Barreto sostiene la hipótesis de la eficacia de la dimensión simbólica ideológica del espacio público moderno para la legitimación de esos procesos de transformación y segregación planificada en Posadas. Este autor entiende las transformaciones urbanas en curso (principalmente la construcción de la Avenida Costanera 
y relocalización de la población asentada en la costa del río a conjuntos habitacionales alejados del centro) como la expresión de ese nuevo orden urbano al que me referí anteriormente, que para el caso Posadas presenta analogías con las primeras ciudades modernas de la revolución industrial europea, cuando se dieron por primera vez procesos de segregación pública planificada. La distinción, acota, está en que son las fuerzas del mercado las que se expresan en las recientes intervenciones urbanísticas.

En ese sentido, los recursos simbólicos vinculados a las imaginerías del progreso cumplieron y aún lo hacen un rol importante en la legitimación de un nuevo orden socio espacial, en especial en ciudades intermedias como Posadas que hasta hace unas décadas aún "disponía en torno al casco céntrico primario, de un espacio urbano residencial sumamente heterogéneo, en el que los diferentes niveles socio-económicos estaban entremezclados” (Barreto, 2002: 56).

El análisis del plano semiótico discursivo revela ciertas operaciones contenidas en los proyectos urbanísticos de diferentes momentos históricos tendientes a imponer representaciones de la costa acordes con los designios de esa forma del capital llamada proyectos de gran escala. La operaciones -prácticas de asignación de sentido inscriptas en la superficie material (Verón, 1996: 129)- que dan forma a la figuración apuntan a transformar el río -antes recurso para la vida- en paisaje, lo convierten en espectáculo, telón de fondo para actividades de consumo según una concepción de espacio público reducida a infraestructura para el comercio y plataforma de contemplación de un espacio en el que ya no es posible vivir sin un alto poder adquisitivo. Se promueve así la legitimación de políticas urbanas que implican la relocalización de la población pobre de las zonas costeras y la generación de mayor rentabilidad urbana para un pequeño sector social.

\section{El discurso de lo urbano}

Tomando los términos de Lefebvre (1972) se trata entonces de trabajar la complejidad de la articulación entre prácticas materiales y espacios de representación. Específicamente las prácticas discursivas asociadas al proceso de transformación de la costa. Para ello trabajé la noción de discurso de lo urbano entendido como "un movimiento de generalización del discurso del urbanista que pasa a formar parte del sentido común sobre la ciudad, produciendo una deriva ideológica que homogeniza el modo de significar la ciudad, sea por el uso indiferente en el discurso ordinario, pero también en el discurso administrativo, del Estado, tomando la forma de lo jurídico y lo político” (Orlandi: 2001: 13). Como toda materia discursiva, el discurso de lo urbano es el resultado de un haz de relaciones del interdiscurso ${ }^{5}$, resultado de la intersección de otros discursos: científicos (urbanísticos, sociológicos, económicos históricos) institucionales, legales y demás. Se trata entonces del tipo de discursividad cuya referencia principal es la ciudad planificada, administrada, es decir aquel que trata sobre la 
organización, control y proyección de lo urbano basado en el conocimiento óptico y las formas de representación espacial propias de la racionalidad moderna.

La operación principal que realiza el discurso de lo urbano es transformar la diversidad de lo real urbano en concepto de ciudad, gracias a una serie de instrumentos y técnicas de proyección que permiten la identificación entre plano y territorio. Por esa operación busca apagar y silenciar lo real, permitiendo manipular el territorio como si estuviera vacío. Se crea de tal forma un espacio abstracto, neutro y homogéneo, propio de las disciplinas proyectivas y prospectivas, que permite disponer los objetos al antojo del planificador.

Lo que a su vez incide particularmente en el tratamiento de la temporalidad, porque la vista en perspectiva proyecta sobre una superficie tratable un futuro tan deseado e imaginado como incierto, ya que su condición de posibilidad es "un olvido y un desconocimiento de las prácticas" (De Certau, 2000: 105). Se dispone en consecuencia un orden urbano que buscando contener y resolver los problemas de la concentración, asigna usos y funciones para cada lugar, define trayectos, conecta rutas, avenidas y calles y por sobre todo interpreta la ciudad, "fija lo que es en cuanto a urbanidad" (Orlandi, 1999: 15). De ese modo el discurso de lo urbano se erige en autor de la ciudad, restringe, define formas de socialidad y de ciudadanía; habla en nombre de ella, del "bien y la razón pública”. Un efecto de monotonía lo caracteriza, porque es el resultado de una voz social homogeneizante. (Orlandi, 2002: 59-60).

Desde esa perspectiva entiendo que el discurso de lo urbano, en su doble condición de discurso oficial administrativo y profesional, construye el objeto costa ${ }^{6}$ y los gestos de interpretación que realiza en esa práctica no sólo orientan la transformación física del territorio sino que además, cuando son puestos en circulación, operan simbólicamente proveyendo al imaginario de la ciudad representaciones de sus espacios que entran en disputa con otros decires ${ }^{7}$. Considero que la generalización que alcanza este tipo de discurso está dada por la legitimidad institucional asignada a la discursividad del urbanista mediante su incorporación al cuerpo normativo municipal -en relación interdiscursiva de dependencia y cooperación con el discurso político y otros- que adquiere así carácter performativo y prescriptivo, habilitando su dispersión hacia otras esferas de la vida humana.

\section{Materiales analizados}

Los materiales de trabajo responden al criterio de dispersión en distintas esferas que realiza el discurso de lo urbano pero delimitado en función de las instituciones que posibilitan su puesta en circulación y le otorgan carácter performativo. De allí que seleccionara los planes urbanísticos, géneros propios de la discursividad del urbanista, así como los instrumen- 
tos legales que validan su contenido: Plan Posadas (PP, 1972); Proyecto Tratamiento Costero (PTC, 1998); Código de Planeamiento urbano (CPU) y ordenanzas modificatorias relacionadas con la zona considerada.

Dadas las limitaciones de este artículo solamente se trabajarán los textos profesionales tomando el inicio y el final de la serie para dar cuenta de las características del objeto costa que van delineando la figuración. De todos modos los demás textos serán mencionados en algunos pasajes de este trabajo así como referencias a otro tipo de materiales (relatos de relocalizados, producciones mediáticas) en los que se constata la dispersión aludida y que forman parte del corpus general del proyecto en el que se enmarca esta investigación.

\section{La figuración del nuevo frente costero}

Los límites y atributos pensados e impuestos a la costa posadeña por el discurso de lo urbano dieron forma, y aún lo siguen haciendo, a un determinado proceso de figuración simbólica de un frente costero para la ciudad. Esto es, aquel proceso de puesta en texto de ciertas representaciones del espacio costero que condensan determinadas visiones del tiempo histórico. Por figuración entiendo el "procedimiento semiótico general que consiste en la concreción de un contenido, aquello por medio de lo cual algo se hace patente de manera clara y recortada"8 (Luisa Ruiz Moreno, 2003:110).

Lo que denomino "un nuevo frente costero para Posadas" es un haz de representaciones de la costa posadeña sobre el nuevo escenario que el embalse de Yacyretá producirá sobre el Río Paraná cuando se eleve a cota 83 m.s.n.m. La posición privilegiada del discurso de lo urbano en el universo semiótico discursivo me permite conjeturar el carácter hegemónico de esas representaciones que pasan a formar parte del sentido común y se reconocen en muchas discursividades, gracias a la amplificación y reiteración mediática de las consignas e ideas contenidas en los planes de intervención costera.

Por su carácter hegemónico las representaciones aludidas tienden a justificar un nuevo estatus de centralidad ${ }^{9}$ proyectado sobre la costa ya que son enunciadas y publicitadas como beneficios para la ciudad apelando al valor simbólico del espacio público moderno. Los efectos de sentido apuntan a opacar los aspectos de la forma proyectada que implican la conformación de una centralidad restringida. Esto es aquellos efectos de la transformación que provocan un tipo de centralidad restringida, entendida como aquellas consecuencias de las grandes intervenciones urbanas que pueden ser derivadas de ciertos esquemas de diseño y que pueden provocar centralidades selectivas y segregadoras (...) enclaves monofuncionales o generar espacios urbanos demasiados estériles a los ciudadanos, imponer un estética dominante y privilegiar intereses económicos frente a intereses de la urbanidad (Licnerski, 2008). 
La figuración se concreta a nivel semiótico discursivo mediante operaciones que ligan las propuestas a un tipo de formación discursiva característica de los procesos de modernización que implican grandes y traumáticas alteraciones socio-espaciales. Revisaré este punto en el apartado que sigue.

\section{La formación discursiva sobre el desarrollo y la posición de sujeto}

Los planes y proyectos analizados asumen la voz de un enunciador universal, que se presenta como no siendo social, por encima de la historia, porque es el lugar desde el cual se dice algo sobre el mundo. Guimarães plantea que un enunciador universal "es un lugar que significa el locutor como sometido al régimen de verdadero o falso. Este lugar es propio del discurso científico aunque no exclusivo de él”10 (Guimarães, 2002: 26).

Asimismo, toda formación discursiva ${ }^{11}$ (FD) delimita un lugar de interpretación, desde el que se produce sentido y subjetividad, puesto que implica la configuración de formaciones imaginarias, que integran la relación entre la situación de enunciación y el contexto sociohistórico. Es decir que en cada FD existen lugares de inscripción para la identificación de los sujetos hablantes, que no necesariamente se corresponden con las personas reales. Comprende entonces un determinado ethos, definido como la instancia subjetiva que se manifiesta a través del discurso; se expresa como "voz" o cuerpo enunciante, históricamente especificado e inscripto en una situación que su enunciación al mismo tiempo presupone y valida progresivamente.

Desde ese marco, entiendo que la "figuración simbólica de un nuevo frente costero para la ciudad de Posadas" es un proceso discursivo atravesado por los componentes ideológicos del desarrollo y caracterizado por interrelaciones de diversos discursos (urbanístico, histórico, económico, jurídico, etc.). La formación discursiva sobre el desarrollo atraviesa y configura el sentido de todos los textos analizados. Las características que la definen contemplan un ethos ${ }^{12}$ modernizador con competencias específicas para controlar el proceso de modernización, la construcción de una temporalidad redentora, la creencia en un movimiento unilineal de la economía y la minimización de los conflictos, todas ellas características de los discursos que acompañan la ejecución de los proyectos de gran escala (Lins Ribeiro, 1999). Los actores que promueven decisiones de estado de orden político-económico como los PGE articulan ideológicamente la necesidad de su construcción mediante un discurso sobre el desarrollo que tiende a concebir el crecimiento económico como un movimiento unilineal y estable iniciado o intensificado por estos megaemprendimientos.

Los proyectos analizados apelan al lugar del decir propio del discurso científico y el efecto que produce este agenciamiento consiste en presentar lo enunciado como única verdad -la verdad científica-, apagando 
así otras interpretaciones que incluyen muchas otras variables para describir el crecimiento urbano, la función urbana, etcétera. Este lugar del decir es una forma de legitimar lo dicho porque es la "voz que se presenta como si los hechos hablasen por sí mismo; se representa siendo todos y cualquiera al mismo tiempo. Determina una posición de sujeto de saber configurado por el funcionamiento de los discursos competentes” (Fontana Zoppi, 1997: 125-126). De ese modo, lo enunciado asume un estado casi incuestionable que es así amplificado cuando las consignas contenidas en los planes circulan en otro tipo de discurso, particularmente en el mediático.

\section{La voz enunciante}

El ethos modernizador es la voz enunciante que se registra en todos los proyectos analizados, desde el Plan Posadas (1972) hasta el Proyecto Tratamiento Costero (1998). Ese ethos conjuga tanto el deseo de autoría como el deseo de comando de todo modelo urbano, descarga en la figura del estado y el planificador las competencias específicas para el dominio del espacio y de tiempo, para controlar el proceso de modernización como si fuera una cuestión exclusivamente técnica. Las acciones de intervención son significadas como si formaran parte de un “destino”, interpretado por el saber planificador.

De allí que ese enunciador universal hable en nombre de la ciudad concepto, a la que cosifica y otorga una entidad propia. Él conoce sus necesidades, sus anhelos y posibilidades, pues posee la autoridad enunciativa ${ }^{13}$, en correlación con los lugares sociales que se apropian de ese lugar del decir, para enunciar la forma ciudad.

Para el caso del Plan Posadas, se manifiesta mediante el impersonal en tercera persona o el nosotros de la comunidad científica, en ciertas secuencias conclusivas o introductorias, los cuasi reflejos. La deixis ubica al enunciador en un espacio nacional. Es la voz de la historia oficial que se sustenta en las citas de autoridad, en la valorización positiva que reciben los personajes y hechos posicionados en lugares dominantes (el estado nacional, el estado provincial y por supuesto, la ciudad cuya voz asume). Entre otros recursos se utilizan: modalización apreciativa mediante subjetivemas de admiración ("estructura perfeccionista, época de avanzada, el más selecto grupo”...), enunciados que van construyendo una categoría semántica del tiempo: lineal anclado al vector progreso. Además de la valoración positiva y el uso del presente genérico que permite construir un conjunto de definiciones que configuran un modelo óptimo. En caso del Proyecto Tratamiento costero sobresalen los enunciados definidores. El enunciador a lo largo del texto equipara y define dos objetos, el proyecto tratamiento costero -el programa de obras con sus resultados esperados- y la costa -el espacio físico a ser intervenido-. Este efecto de equivalencia se produce porque la zonificación o división en sectores del perfil costero de la ciudad ${ }^{14}$ se realiza mediante un proceso de nominación por el cual cada pieza del tratamiento costero pasa a designar al mismo tiempo el espacio 
físico a intervenir y la función asignada a ese espacio.

Una vez producido el ingreso al archivo de legislación urbana, el Código de Planeamiento Urbano, las decisiones particulares sobre el territorio, la población, el medio ambiente, mediante procedimientos de universalización y abstracción de modalidad lógico formal, pasan a designar categorías, entidades. Y se desliza la responsabilidad por las aserciones y definiciones a un enunciador universal, un sujeto de saber, ubicado fuera de la historia y lo social, configurado por un discurso competente (el discurso urbanístico). Al reificar la discursividad del urbanista la inscripción en el archivo produce un cierre y de ese modo refuerza la política de silenciamiento del discurso de lo urbano: la multiplicidad de discursividades que componen la ciudad. Así, queda cristalizada en un decir circular, auto referencial, ya sea para regular como para exceptuar.

Se produce así un efecto monofónico resultado de una voz social homogeneizante que asume la representación del estado y la sociedad; "que hace parte del mecanismo articulado entre el silenciamiento y la inducción al decir -reproducción de un discurso instituido-, puesta en práctica por mediadores que distribuyen socialmente los sentidos" (Orlandi, 2004: 60). Lo que se genera es un efecto de una ilusión de exterioridad ${ }^{15}$, porque el ethos es dotado de un excedente de visión, que le permite ver el futuro, pronosticar su evolución y anticipar las soluciones. Es decir le son asignadas las competencias para planificar la forma futura de la ciudad. Gracias a la figura del enunciador universal los urbanistas pueden abstraerse del campo social que los incluye en la producción del espacio social. Ese dislocamiento al tiempo que legitima la perspectiva de enunciación, oculta la dimensión política del pensamiento técnico.

\section{El cronotopo de las grandes obras}

El proceso de figuración también se caracteriza por lo que denomino "cronotopo ${ }^{16}$ de las grandes obras" para aludir al valor figurativo y valorativo que adquiere el proyecto Yacyretá en la construcción de la imagen de la nueva costa posadeña. Desde esa particular coordenada espaciotemporal se da sentido a las distintas propuestas, tanto la formulada en 1972 como en 1998 incluso bajo paradigmas opuestos. Se sustenta así una visión optimista de los proyectos planificados (en la escala regional y urbana), asociada a la red léxica del campo del progreso: “crecimiento", "pujanza”, "evolución sana”, "cambio fundamental”.

El cronotopo proyecta una ciudad futura en el cuadro regional y define un rol: nudo de tráfico internacional y centro de intercambio regional sostenido por los beneficios que traerán las grandes obras. Éstas definen la imagen ciudadana, permitirán que la ciudad encuentre su rol en la región y en el país: modelarán el espacio urbano futuro; traerán "crecimiento y pujanza" si se afronta el desafío con "imaginación y audacia”, como se prescribe en el Plan Posadas. 
Se trata de una temporalidad anclada en la formación desarrollista cuyo ethos modernizador representa el gesto moderno de transformación del "río vivo en río visto". De ese modo, el carácter conflictivo de las obras -el desplazamiento forzado de la población ribereña que obtenía del río sus recursos y la alteración irreversible del ecosistema- son tópicos eludidos por el discurso de urbano. La proyección de la costa, entonces, se realiza elidiendo sistemáticamente toda referencia a la vida social existente al momento de iniciar la implementación del proyecto.

La actitud frente al tiempo es la de un sujeto que asume la tarea de ejecutar una voluntad de forma colectiva, imaginada y proyectada para que la ciudad pueda sacar "ventaja" del movimiento unilineal de crecimiento económico. Son los planificadores, mediante el plan, los encargados de ejecutar esa voluntad.

Así el cronotopo de las grandes obras permite configurar esa visión de futuro, movilizando los componentes ideológicos del mito del progreso histórico que tanto preocupó a Benjamin. Temporalidad, concebida "bajo el signo mítico de la predeterminación por el que la gente se convence de que el curso actual de los acontecimientos no puede ser resistido" (Buck Morss, 2001: 95), con la que se valoriza el gigantismo como metáfora del progreso, la creencia en el cambio acelerado y las perspectivas panorámicas de la fantasmagoría urbana.

\section{El Plan Posadas y la consigna de transformación}

El proceso de figuración comienza con la formulación del primer plan urbano pensado a partir del escenario que provocará la represa Yacyretá sobre la ciudad. Se trata del Plan Posadas cuya primera versión se realizó en 1972 orientada por lo que denominé una matriz discursiva ${ }^{17}$ racionalista regional caracterizada por una directriz incluyente, el anhelo de integración. El componente racional está dado por el apego al paradigma normativo y a un orden tipo característico del Movimiento Moderno, la creencia en el progreso universal y la razón instrumental. En tanto que el componente regional se configura por las transferencias teóricas de otras corrientes del pensamiento urbanístico, especialmente Mundford, recepcionadas y resignificadas por una vanguardia arquitectónica nacional cuya preocupación principal eran las provincias y la búsqueda de una estética regional. Concebían la región como unidad de planeamiento y al río como un elemento estructurante de la planificación. Las relaciones de sentido entre los componentes programáticos de la visión racionalista regional y las particulares condiciones de producción del PP se materializan en voluntad de forma a partir de un componente estructurante, el río. Junto con la infraestructura básica (estructura vial y extensión de servicios) permitiría la unificación del tejido disperso y ordenaría la futura expansión de la ciudad mediante la aplicación del zooning. De esa manera, se forma la imagen de una costa esqueleto. Con este sintagma recupero la metáfora que remite a la estructura básica del plan que así como el esqueleto sostiene al cuerpo hu- 
mano, aquella lo hace con la ciudad al estructura su crecimiento. Enfatizo de ese modo la imagen organicista y abarcadora de todo plan urbano.

La argumentación de la prognosis se construye en base a un efecto de sustentación (Pêcheux, 1995) a mayor infraestructura, mayor crecimiento y por ende progreso. Se distingue de las figuraciones posteriores por su anclaje en el pensamiento moderno y las condiciones físicas de la ciudad (menor densidad ocupacional y espacio edificado, islotes de crecimiento dispersos).

En este marco se formula una consigna que será retomada en todos los proyectos posteriores y elevada al rango de mandato a cumplir por el discurso político: abrir la ciudad al río. La consigna apuntaba a conectar el río con las áreas de viviendas, que ese entonces se encontraban dispersas, ya que otra de las acciones del plan es densificar la ciudad. Esta intención urbana será retomada por distintos actores sociales y circulará en todo tipo de discursividades - por ejemplo en los relatos de relocalizados, las conversaciones cotidianas de vecinos, las expresiones de agentes inmobiliarios-, confirmando la hipótesis de dispersión del discurso de lo urbano.

Las futuras interpretaciones de la consigna bajo nuevos paradigmas de planificación, que ya siguen los dictados del mercado sin mayores pretensiones, disolverán la directriz incluyente -de sesgo humanista y optimista- y el propósito del urbanismo moderno: integrar la totalidad del tejido urbano. Éste se articulaba con la concepción del Estado de Bienestar que contradictoriamente se proponía dotar a la sociedad de una estructura de integración social a través de políticas redistributivas; al mismo tiempo que avalaba un modelo urbano de segregación social y segmentación espacial como el paradigma normativo ${ }^{18}$.

Claro que esta concepción contrastaba con las particulares condiciones políticas e institucionales en las que se diseña el Plan, que remiten a otra orientación valorativa de la voluntad de forma, ligada a la impronta militarista con la que se imponía el capitalismo transnacional en América Latina.

Por otra parte, el anclaje del Plan Posadas en la formación discursiva sobre el desarrollo se evidencia en la construcción del objeto "costa” al iluminar los preconstruidos ${ }^{19}$ de dicha formación. En el Plan Posadas esto se registra en la sobre- ponderación de la propuesta de intervención como "la solución esperada", cuando se argumenta que el destino y el futuro de la ciudad está inexorablemente atado a las grandes obras derivadas de Yacyretá y se minimiza el carácter conflictivo del proyecto (impactos medioambientales, urbanísticos, sociales en toda la zona de afectación, etcétera).

Es así como las racionalizaciones geográficas en la localización del capital (Harvey, 1998) son significadas desde una perspectiva modernizadora como las etapas de una línea de evolución histórica hacia un ideal urbano. 
El efecto de sentido consiste un "naturalizar" la reconfiguración socioespacial que hace a un factor de producción como el de Yacyretá. Por ese efecto quedan minimizados los impactos sociales y políticos que ellas implican; que por cierto al momento de la formulación del plan eran mucho menores que en el momento en que efectivamente se desarrollaron.

\section{El Proyecto Tratamiento Costero y la ejecución de la consigna}

Décadas más tarde, el contexto había cambiado. Los años noventa se caracterizaron por la implementación de políticas neoliberales vinculadas con la reforma del estado y un programa de ajuste como parte de las requisitorias de organismos internacionales para la liberación de créditos. Presentado con una retórica de participación y fortalecimiento de las gestiones locales, este proceso funcionó en la práctica como un modo efectivo para que el estado nacional se desentendiera de gran parte de sus funciones básicas que implicaban importantes erogaciones fiscales.

En el caso de Misiones, estas políticas se implementaron en parte por la alineación política al gobierno nacional y por las estrechas relaciones entre el estado provincial y grupos económicos nacionales y transnacionales con intereses en la obra pública (entre ellos el Grupo Macri). Contribuyeron con este estilo de gobierno el impacto de las grandes inversiones que la Entidad Binacional Yacyretá (EBY) realizó durante la década del noventa en la ciudad y la provincia, especialmente durante los últimos años, cuando se disiparon las dudas sobre el financiamiento de las mismas.

En este contexto se realiza la última reformulación ${ }^{20}$ de la voluntad de forma con el Proyecto Tratamiento Costero ${ }^{21}$. El diseño consiste en un "sistema de piezas articulables", orientado a proyectar sobre la costa la estructura urbana de la ciudad y reproducir las condiciones particulares de cada sector afectado según los criterios de: “compensación”, “reposición funcional”, "restitución” y "recomposición”. Estos términos aluden únicamente a la ciudad edificada y excluyen las referencias al tejido social desarticulado.

Para analizar el proyecto utilicé nuevamente una metáfora: la “costa en pedazos" para referirme a rasgos que lo inscriben en un nuevo paradigma de planificación caracterizado por la preeminencia de los denominados "proyectos urbanos" orientados a la recalificación de áreas y la generación de centralidad (servicios terciarios) en áreas degradadas -waterfront-, parques urbanos corredores y nodos viales. El caso analizado exhibe ciertas relaciones dialógicas que ligan los proyectos imaginados con ciertos componentes ideológicos orientados a la competitividad de territorios y la concepción de espacios públicos como lugares nodales de cualidad (Borja, 2005; Talesnik, \& Gutierrez, 2002). Dichas tendencias "propusieron una concepción de ciudad por partes, que flexibilizara la visión "totalitaria" de 
la planificación tradicional, poniendo el énfasis en la capacidad de la arquitectura para producir forma, tanto en el plano de las necesidades identitarias de la ciudadanía como en el valor de commodities de los edificios y sitios urbanos” (Gorelik: 2004: 241).

La Costanera sector IV -noreste- es considerada el segmento que dará a Posadas una Nueva Fachada. Allí se proyectó un nuevo frente edificado en altura que aproveche las visuales al río, una Villa Cultural que incluyó la demolición de la ex Estación de Trenes (que había sido recuperada por sectores de la cultura años atrás) ${ }^{22}$.

En general, predomina la caracterización de la costa como centro, respaldada por un segundo enunciador (el Plan Posadas). La inscripción en la formación discursiva sobre el desarrollo se constata también en la reiteración de la representación de un futuro ordenado y la creencia en que la inyección de actividades terciarias en el sector mencionado significará un beneficio para toda la comunidad.

"Siguiendo las directivas del Plan Posadas, se ha optado por considerar a este sector como la proyección del centro de la ciudad sobre el eje costero. Dada su cercanía con la actividad portuaria y ferroviaria, este sitio fue elegido como emplazamiento de establecimientos industriales y de servicio, creciendo a sus alrededores barrios de trabajadores” (PTC, 1998: 13).

A partir de la activación del PP como referente textual de autoridad para las proposiciones que el enunciador postula, se concreta una operación de reformulación discursiva al poner en boca de los autores de aquel documento lo que se dice en el presente de la enunciación. Se busca legitimar así la nueva voluntad de forma y asociar el nuevo frente costero a la imagen de futuro formulada por primera vez en 1972 bajo otro paradigma y en un contexto bien diferente. Con la mención al Plan Posadas como texto inspirador se sustenta en dicha fuente la legitimidad del enunciado nuevo.

A su vez, los centramientos que van definiendo el objeto discursivo Avenida Costanera Este aportan información sobre cómo es concebido ese espacio:

"se ha considerado este sector como" "proyección del centro de la ciudad sobre el eje costero".

(La medida) "permitirá que este sector se desarrolle como un nuevo frente edificado".

"Buscando que este fragmento constituya una pieza coherente, cuya armonía consolide su carácter de nueva fachada de la ciudad de Posadas “

(...) "pasando a ser el asentamiento natural de las actividades terciarias". 
En la primera entrada la costa es definida como proyección del centro apelando a un antecedente de autoridad, mientras que en las que siguen se especifican los resultados esperados de la intervención determinando gradualmente la primera definición. Es decir, se detalla qué se entiende por proyectar el centro sobre el eje costero: aumentar el valor del suelo, construir nuevos edificios en altura y habilitar el uso del suelo para las actividades comerciales y de servicio.

Por el procedimiento de filtraje se retoman determinados aspectos del objeto vinculándolos al PP -la intención de formar un paisaje con visuales al río para el área- pero al hacerlo se "filtran" los destinatarios y el escenario original de aquella medida. El contenido previo del objeto -que remite al PP-es acomodado a lo que se tiene intención de decir: delimitación de un sector con altos valores del suelo para el desarrollo del mercado inmobiliario, comercial y de servicio y que promueve una nueva modalidad residencial (edificios de altura) que altera los modos históricos de habitar ese espacio. Es decir, una vez retomada la caracterización de este sector de la costa como centro respaldada por un segundo enunciador se la despoja de sus vinculaciones con los barrios obreros, las actividades ferroviarias y portuarias para incentivar las del comercio y el mercado inmobiliario.

En el último de centramientos el calificativo "natural” realiza una determinación sobre el objeto que resalta el razonamiento desplegado y revela la fuerza argumentativa del proceso de referenciación ${ }^{23}$ orientado hacia la aceptación de la conclusión: los sectores de mayor valor son los apropiados para el asentamiento de las actividades terciarias; o si se admite otra paráfrasis: los sectores de mayor valor son "naturalmente" destinados a las actividades comerciales y de servicio. Se otorga así valor de regla, de norma universal, a las decisiones singulares que representan cada una de las medidas adoptadas.

\section{Dispersión y acentuación}

Los sectores dominantes que producen los cambios y las reestructuraciones espaciales hacen uso frecuente de la eficacia simbólica del ethos modernizador y de la imagen que emerge de la figuración. Ciertos actores se valen de aquel para reafirmar su poder o posición, como lo muestran diversas reformulaciones de la idea fuerza "abrir la ciudad al río".

"El escenario urbano y paisajístico de la ciudad experimenta una gran transformación con la construcción de la Avenida Costanera obra largamente anhelada- que ha sido una apuesta firme de la acción conjunta del Municipio y la Provincia con el apoyo de la EBYa la que se sumará el inminente tratamiento costero a cargo de la EBY, emprendimiento que permitirá redescubrir un paisaje nuestro, tal vez tan ignorado como el del Paraná que hará que los posadeños y visitantes vivan el y del río” (Ing. Carlos Rovira) 
En esta cita la consigna es reelaborada como 'redescubrimiento del río’ y utilizada para promocionar y enfatizar la capacidad ejecutiva de quien ocupara el cargo de intendente de la ciudad (1994-1998) cuando se comenzó la construcción de la Avenida Costanera (durante su mandato se culminó el primer tramo). La obra fue utilizada como símbolo de su gestión para respaldar su proyección política hacia la gobernación (1999-2007).

Los agentes inmobiliarios, fuentes consultadas frecuentemente por los medios de comunicación, algunos con pautas publicitarias, también reproducen la idea fuerza para vender el nuevo paisaje y promocionar los nuevos lotes disponibles revalorados por las obras del tratamiento costero.

“Somos una ciudad que mira al río” (María Giménez, corredora inmobiliaria)

"Un balcón hacia el río Paraná” (nota Ocupar Espacios en el Suplemento NEA N 31, diario El Territorio, 2005)

Pero la figuración del Frente Costero no siempre es acentuada positivamente. Las diferencias en el espacio social en el que se dan las transformaciones se registran en el campo discursivo mediante "agenciamientos" enunciativos particulares por parte de los “afectados” por las obras. Ellos hacen uso frecuente de la primera persona (singular o plural), que expresa una subjetividad reorganizada frente a la emergencia de lo nuevo, apelan a la construcción de nosotros diferenciado, el de los excluidos, el de los pobres.

Por la distribución desigual los discursos, el lugar de interpretación de la formación discursiva sobre el desarrollo -la temporalidad que auspicia la perspectiva del progreso- se impone sobre quienes son expulsados de la costa. Se vuelve ineludible en el plano enunciativo ya que los interlocutores de los relocalizados no son solo el Estado y la EBY sino también aquel sujeto anónimo y abstracto en cuyo nombre habla el ethos modernizador, la ciudad y co-extensivamente la región. Los perjudicados adoptan diferentes acentuaciones y valoraciones sobre las transformaciones de acuerdo al nivel de aceptación de las mismas y la autoevaluación de sus propias condiciones de vida. Los fragmentos que siguen ejemplifican cómo las voces de los desplazados se posicionan en relación a ese cuerpo enunciante de las representaciones hegemónicas, para rechazar, aceptar o negociar la idea de progreso que éste reproduce.

"La palabra afectado -nos dice- te abarca todo. Estás afectado, estás infectado, estás rechazado... No sé, hay tantas cosas...., el afectado es una persona muy sufrida, marginada, parece que los pobres no nos merecemos vivir cerca del río ¿̇no?” (Yeni, vecina de El Brete).

"Por eso yo siempre le digo a ellos que esto nos va a servir de 
experiencia. Un día esto va a terminar... sabemos que tenemos que irnos. Nunca vamos a poder contra el progreso. Porque yo también estoy de acuerdo con el progreso, pero no así, al costo del sufrimiento de mucha gente." (Silvio Alvarenga, vecino de El Brete)

Si el ethos modernizador es el cuerpo enunciante del desarrollo y el progreso -ideales legitimadores de los cambios producidos- que habla en nombre del Estado y la sociedad, los relatos de relocalizados muestran la no inclusión en ese cuerpo que aflora en el discurso con el testimonio del trauma del desplazamiento en primera persona.

Es que el dispositivo enunciativo de la formación discursiva sobre el desarrollo se caracteriza por la interlocución asimétrica. Al asumir la visión de futuro y la posición de un sujeto de saber y un régimen de verdad, el ethos discursivo instala a los demás sujetos del discurso en una relación desigual. Las designaciones y la lucha por el sentido de las mismas son indicadores de esa asimetría en la enunciación. La nominación 'afectados' es una categoría administrativa elaborada por la Entidad Binacional Yacyretá para agrupar a los moradores de la zona costera ubicados en el área de expropiación. Se la utiliza para designar a los 'beneficiarios' del Plan de Reasentamiento y Rehabilitación (PARR). En el marco de luchas reivindicativas de los sectores desplazados, esta nominación fue resignificada tratando en algunos casos de incluir a toda la comunidad con el objetivo lograr el apoyo de otros sectores menos vulnerables apelando a los daños ambientales y las pérdidas simbólicas. Es el caso de un dirigente relocalizado que logró llevar un caso colectivo hasta la Corte Suprema de Justicia, quien dice

"Afectados somos todos y eso es lo que tenemos que darnos cuenta, porque con Yacyretá perdemos todos, nuestros hijos, nuestros nietos. Yo ya perdí, pero creo que mi lucha no es en vano” (Brígido Olivera, Barrio El Zaimán).

Existen muchos otros sentidos asignados a la nominación que no cabe tratar aquí pues hacen a los procesos reivindicativos que ameritan un tratamiento especial. Basta señalar lo que plantea Arach respecto del uso de la noción "La identidad del afectado fue un constructo para lograr legitimidad como interlocutor frente a la EBY, pero también frente al estado y la sociedad de pertenencia, de un amplio conjunto de excluidos que veían reconocidos en el plano formal pero negados en el plano real sus derechos como habitantes de un estado nacional” (2005: 91).

Los ejemplos trabajados exponen parte de la complejidad del proceso discursivo de figuración del espacio costero, al exponer sus contrastes más evidentes. Entre los que resaltan la configuración de la subjetividad del afectado -correlato de la formación discursiva sobre el desarrollo- así como el Nuevo Frente Costero trastocado en símbolo de gestión en el discurso político. 


\section{Conclusión}

El objetivo de este trabajo ha sido presentar un abanico de operaciones desplegadas para la construcción del objeto discursivo "costa" considerándolas parte del proceso de figuración del nuevo frente costero para la ciudad de Posadas, imaginado y proyectado en el discurso de lo urbano como expresión de una voluntad de forma. Esto es la dimensión ideológica de la organización del espacio, expresión política del proyecto urbano) una solución imaginada para relacionar la ciudad y el río. Proceso aún en desarrollo, valorizado positivamente desde el discurso político y de lo urbano como una oportunidad de desarrollo, que impulsa la ciudad hacia adelante y trae ciertos aires de modernidad a Posadas; pero que al mismo tiempo margina a los sectores más empobrecidos, expulsados hacia una periferia urbana lejos de la centralidad de la ciudad.

Lo analizado me conduce a pensar el papel de la imaginación en toda producción simbólica, entendida siguiendo a Castoriadis como condición operante de toda significación ulterior, como la capacidad para definir un orden del mundo y producir visiones del conjunto de la experiencia humana, que constituyen lo que denomina significaciones imaginarias o imaginario efectivo (lo imaginado), el factor unificante que proporciona significado al mundo. Con la modernidad el orden de lo imaginado plantea una paradoja: ésta empuja la racionalización hasta el límite, pero el contenido con el que trabaja es del orden de lo imaginario.

Si se considera la modernidad como discurso (Bruner, 1992), el proceso de figuración simbólica emerge como manifestación de éste, en tanto es el resultado de una práctica discursiva concreta, un constructo de la imaginación urbanística. Es la expresión simbólica de una modernidad local, articuladora de la tensión (constitutiva de su definición) entre su condición de facultad creadora (de espacios y sentidos) y de racionalidad técnica, característica de la modernidad (Castoriadis, 1993, Barbero, 2004). Es que si bien la matriz civilizadora de la modernidad ha alcanzado expansión mundial, dicho proceso socio-cultural se ha realizado a través de diferentes formas históricas "la historia de los países latinoamericanos subraya esa diferencialidad” (Ortiz, 2000: 9). Considero que el corpus analizado puede ser abordado como una manifestación concreta de una modernidad tardía, en una ciudad como Posadas, periférica y fronteriza, en la que el comienzo y el fin del ciclo expansivo de la ciudad asume particularidades propias. En esa línea, las indagaciones sobre la dimensión simbólica ideológica de las prácticas de representación espacial, las operaciones discursivas y cierta retórica de los proyectos de intervención sobre el territorio, intentaron ser aportes para pensar el sentido que adquiere en ciertas discursividades "lo moderno" y la “modernización”. En esta versión local de la modernización, el estado asume la inversión del capital principal acondicionando la infraestructura (y acá podríamos incluir además el debate de los contratos de licitación que ha favorecido en general a los intereses privados fuertemente ligados al poder político) allanando el camino para la posterior etapa de la modernización de superficie que ya comienza a tomar fuerza con la 
construcción de emprendimientos privados en el nuevo tramo de la costanera. Como señala Gorelik "modernizando en la superficie se invierte poco y se gana mucho: por ello es un tipo de modernización ideal para el modo en que operan los intereses privados en la ciudad, aunque también el poder público encuentra rédito en las imágenes de superficie” (2004: 232). Las tensiones registradas en el discurso de lo urbano son parte de esa funcionalidad ficcional que adquieren los planes y proyectos de remodelación urbana, en tanto artefactos culturales a través de los cuales se implementa dicha modernización de superficie. En definitiva mi interés por analizar las formas simbólicas de una modernidad local, retomando las palabras de Gorelik, se inspira en el objetivo de "cuestionar el presente, porque no se puede comprender lo que no se quiere transformar” (ibíd.: 139). 


\section{Notas}

*Este artículo presenta algunos resultados de mi investigación para el Doctorado de Semiótica por la UNC, y forma parte de un proyecto de investigación titular "Espacio, Comunicación y Cultura III”, bajo la dirección de Mgter. Elena Maidana que tiene por objetivo analizar la relación entre ciudad vivida y ciudad proyectada. Parte del material de análisis utilizado en este artículo corresponde al citado proyecto.

${ }^{1}$ La represa Yacyretá es uno de los complejos hidroeléctricos más importantes del continente, fue construida por un acuerdo bilateral entre los gobiernos argentino y paraguayo, emplazada sobre el Río Paraná a la altura de las poblaciones de Ayolas (Paraguay) e Ituzaingó (Argentina), a 90 km. de Posadas, genera un lago de 140.000 hectáreas, de las cuales 30.000 afectan a territorio argentino. El impacto en la ciudad es la inundación del 8,24\% del territorio, alrededor de 3.000 propiedades y la relocalización de más de 7.000 hogares (un total de 18.004 familias -9.031 en Argentina y 8.973 en Paraguay-, representando aproximadamente 80 mil personas).

${ }^{2}$ Desde la Sociología urbana se ha descrito este fenómeno en el marco de la lógica cultural del capitalismo tardío que impulsa el desarrollo del turismo urbano a partir de los proyectos de reestructuración urbana orientados a situar a cada ciudad en la posición más favorable en un escenario global cada vez más competitivo (Harvey 2007; 1998; Díaz Orueta, 2005).

${ }^{3}$ Los procesos discursivos actúan estableciendo relaciones de sentido (parafrásticas, polisémicas, de presuposición, de contradicción, etc.) entre el dominio de lo dicho, de lo decible y del silencio, pero también representan una manera de decir, un tono y un cuerpo imaginario constituidos por las posiciones de sujeto establecidas en las formaciones discursivas del interdiscurso (Fontana Zoppi, 1998: 120).

${ }^{4}$ Con el ejemplo de la intervención de Haussmann en la ciudad de París como paradigma de la expansión sociocultural de la modernidad, Barreto plantea que desde entonces el espacio urbano asumió el carácter ideológico público obedeciendo a la manera en que se configuró la esfera pública moderna en el campo político. Este carácter público del espacio urbano moderno reconfiguró la ciudad "a partir de la concepción de un espacio urbano capaz de integrar la totalidad de la ciudad en un sistema unificado de circulación y actividades y la inducción hacia la especialización de las actividades, comerciales, industriales, recreativas y residenciales, segmentadas bajo el imperativo de las nuevas clases sociales y los nuevos patrones de consumo -incluido en ellos, los del propio suelo urbano-, readecuaron con sentido moderno las relaciones entre lo público y lo privado en la vida urbana de la ciudad” (Barreto, 2004: 257).

${ }^{5}$ Las relaciones entre distintos tipos de discurso en una serie temporal dada. Esta última noción es clave para la perspectiva trabajada en este artículo, se lo define como las mutuas delimitaciones que se producen en el universo de los discursos, amplitud de lo decible y de lo pensable, siempre en relación con las formaciones sociales e ideológicas que lo atraviesan (Maingueneau, 2003; Fontana Zoppi, 1998). En este sentido se utiliza la noción de interdiscurso como sinónimo de memoria discursiva.

6 "El objeto discursivo es asociado a un haz de aspectos que incluye propiedades, relaciones y esquemas de acción. Se asienta en preconstruidos culturales, es decir en un conjunto de conocimientos compartidos por los miembros de un grupo, dan lugar a representaciones que presentan zonas más o menos vagas, desencadenadoras de distin- 
tos efectos de sentido” (Arnoux, 2008: 125).

${ }^{7}$ Para un relevamiento de las dispersiones del discurso de lo urbano ver Maidana Elena (2006) “Informe Final. Proyecto Espacio Comunicación y Cultura II”. Secretaria de Investigación y Postgrado. Facultad de Humanidades y Ciencias Sociales. Universidad Nacional de Misiones, Argentina.

${ }^{8}$ El proceso de figuración genera y contiene el proceso de iconización desplegada en cada texto; la iconicidad es el resultado de un conjunto de procedimientos semióticos que tienen a producir efecto de sentido o impresión de realidad, siempre modalizado por la cultura.

${ }^{9}$ La idea de centralidad urbana hace referencia a la capacidad de ciertos espacios o elementos urbanos de articular flujos de todos los tipos y depende del grado de influencia de estos espacios sobre los demás componentes del sistema urbano. Tradicionalmente, la noción de centralidad se limitaba a la parte central del espacio urbano por su complejidad espacial y por concentrar diversas actividades urbanas. Sin embargo, con el crecimiento de las ciudades y la dispersión de las actividades urbanas, se produce la formación de nuevas formas de centralidad urbana. La caracterización de estas nuevas formas de centralidad se presenta diversificada en sus configuraciones espaciales y en sus formas de implantación (Licnerski, 2008).

${ }^{10}$ Desde la perspectiva de una semiótica discursiva y siguiendo a Guimarães, lo político atraviesa el lenguaje a partir de la definición de "agenciamiento político de la enunciación”. Los lugares enunciativos son configuraciones específicas de agenciamiento enunciativo constituidos por los lugares del decir para aquel que habla y aquel a quien se habla. Se distinguen entonces lugares sociales desde los que se habla (un urbanista que formula planes de intervención) y lugares del decir, que son aquellos desde donde se produce el agenciamiento de la enunciación. Estos lugares pueden ser: enunciador genérico, enunciador universal o enunciador individual.

${ }^{11}$ El concepto aparece formulado por primera vez por Michel Foucault. E ingresa luego al análisis del discurso vía Michel Pêcheux en relación con el concepto de formaciones sociales de Althusser para designar "todo sistema de reglas que fundamenta la unidad de un conjunto de enunciados socio históricamente circunscriptos (...) posicionamientos ideológicos marcados que compiten en un campo discusivo" (Maingueneau, 2003: 52), ese "juego de equilibrios inestables" en el interdiscurso (ibíd.: 19), espacio de lo decible / lo no decible; lo enunciable /lo no enunciable.

${ }^{12}$ Resulta de la interacción del ethos prediscursivo (representaciones del locutor) y del ethos discusivo mostrado o dicho. El ethos efectivo es el resultado de estas diversas instancias cuyo peso respectivo varía según los géneros de discurso (Maingueneau, 2004)

${ }^{13}$ La autoridad enunciativa es una función del enunciador que incide sobre los comportamientos de los sujetos respecto de un discurso. La validez de las proposiciones de ese sujeto se desprende de la autoridad del enunciador. Designa "la función que le confiere al enunciador el estatus que se le reconoce” (Maingueneau, 1996: 8)

14 “1) Sector Arroyo mártires, 2) Sector Costa Natural; 3) Sector Bahía El Brete; 4) Sector Costanera Norte; 5) Sector Costanera Este; 6) Sector Franja de Transporte Norte; 7) Sector Arroyo Zaimán Superior; 8) Sector Arroyo Zaimán Inferior” (PTC, 1998: 7). 
${ }^{15}$ El efecto se crea "cuando el locutor representa discursivamente como aquel cuya perspectiva de enunciación es siempre ya legitimada, fuera y antes de cualquier relación de interlocución. Se constituye imaginariamente como aquella que posee un excedente de visión” (Fontana Zoppi, 1997: 13-12).

${ }^{16}$ Categoría generalizadora, semántico valorativa que se resuelve en motivos concretos o figuras textuales (Arán, 2006: 69). Es un centro organizador de los acontecimientos representados en el texto, que enlaza los nudos argumentales. Determina tanto la forma como el contenido del texto así como la imagen de sujeto porque es el resultado de una conciencia situada. Es un indicador de la actitud frente a la realidad que asumen los autores, el punto de vista desde el que evalúan lo representado en el texto, ya que constituye la encarnación del tiempo y el espacio en el discurso, un centro de concreción plástica para el mundo representado (Bajtín, 1989: 400).

${ }^{17}$ Definición tomada de Jean Claude Beacco con la que se alude a "un espacio común donde se generan discursos que comparten ciertas regularidades, molde que permite dar forma discursiva a datos diversos" (citado por Arnoux, 2008: 54); funciona a "modo de grilla de interpretación, marco con valor modelizante del cual preceden en grados de conformidad variable los textos observados que entran en una misma serie” (ibíd.: 98).

18 "El capitalismo lucha perpetuamente por crear un paisaje social y físico a su propia imagen y exigencia, para sus propias necesidades en un momento determinado en el tiempo, sólo para ciertamente debilitar, desestabilizar e incluso destruir ese paisaje en un momento posterior en el tiempo. Las contradicciones internas del capitalismo se expresan mediante la remodelación y recreación continua de paisajes geográficos” (Harvey, 2007: 354). La paradoja se resuelve, según Harvey (2007), puesto que esa fue la forma que encontró el capitalismo para resolver temporalmente sus propias contradicciones y mitigar la lucha de clases configurando un nuevo orden social y espacial productivamente eficiente al incrementar el consumo y la producción conjuntamente con la acumulación de capitales.

${ }^{19}$ La iluminación es "un conjunto de procedimientos discursivos que deben conducir al oyente lector a inferir un juicio de valor" (Arnoux, 2008: 47); mientras que el anclaje son los signos indicadores que remiten a un conjunto de significaciones preconstruidas. Las operaciones de enriquecimiento especificación extraen o inyectan aspectos de un haz establecido por el anclaje (ibíd.). Los preconstruidos son "sistemas de saberes tanto cognitivos como afectivos, (...) que sirven de base a toda acción y en el que todo pensamiento se ancla” (Grize citado por Arnoux, 2006: 69).

${ }^{20}$ Siguiendo a Elvira Arnoux, el análisis de las reformulaciones es un tipo de abordaje permite analizar las condiciones socio históricas de producción de los textos, las representaciones de la nueva situación de enunciación; ya que las "huellas de la reformulación se vuelven indicios -a partir de la puesta en relación con saberes del campo en el que se inscriben los discursos analizados- de las condiciones de producción y de recepción de los textos” (2006: 97-98). En este sentido, “citas, comentarios y reformulaciones son gestos interpretativos derivados de lecturas cuyas huellas se exponen en el recorte, el entorno elegido, la focalización, la opción parafrástica, la orientación argumentativa en la que se enmarcan. La diversidad de interpretaciones permite despliegues múltiples en ese volver a decir los textos fuente" (Arnoux, 2007s/n).

${ }^{21}$ Fue elaborado por una consultora en el año 1998, aprobado por el Concejo Deliberante de la ciudad en 2001 y actualmente se encuentra en ejecución como parte del Plan de Termina- 
ción de Yacyretá (PTY) ${ }^{21}$ en el que finalmente se enmarca el Proyecto Tratamiento Costero. El nuevo plan fija como plazo final el año 2010 y cuenta por primera vez con financiación del presupuesto de la Nación Argentina, además de un fideicomiso con el Banco de Inversión y Comercio del Exterior. Estos organismos son los que financian las obras que actualmente se encuentran en ejecución.

${ }^{22}$ Las obras incluyen: restauración y refuncionalización arquitectónica de $1.750 \mathrm{~m} 2$ de edificación existente; construcción de un Nuevo Módulo de edificación de 700 m2; talleres y Albergues para actividades culturales; museo Ferroviario; construcción de un mini teatro exterior para funciones artísticas; área reservada para desfiles; iluminación y sonidos aptos para televisación.

${ }^{23}$ Según Villaça Koch, "la referenciación es una actividad discursiva que implica elecciones significativas de acuerdo a las necesidades de interacción, dentro de los múltiples medios de expresión que ofrece la lengua” (2002: 10). El supuesto que sostiene esta definición es la inestabilidad entre las palabras y las cosas y una concepción de los objetos discursivos dinámica que entiende que los referentes textuales son objeto de discurso. La determinación del referente es uno de los procedimientos frecuentes en la construcción intradiscursiva de los objetos del discurso. 


\section{Bibliografía}

Arán, P (2006) (2006), Diccionario de la Teoría de Mijaíl Bajtín. Ferreyra Editor, Córdoba.

Arnoux, E (2008), El discurso Latinoamericanicista de Hugo Chávez. Biblos, Buenos Aires.

Arnoux, Elvira N. y Blanco M (2007), “Cita, comentario y reformulación en la travesía de un fragmento del Nuevo Testamento”, en Tópicos del Seminario $N^{\circ}$ 17, Universidad Autónoma de Puebla, Puebla. Disponible en http://www.semiotica.buap.mx/

Bajtín, M. (1989) Teoría y Estética de la novela. Trabajos de Investigación, Taurus, Madrid.

Barreto, M (2004) Transformaciones de la vida urbana de Posadas y Resistencia a fines de los años '90. Un estudio sobre la dimensión simbólico-ideológica del espacio urbano público. Tesis doctoral, Programa de Postgrado en Antropología Social, Universidad Nacional de Misiones, Posadas.

Ídem (2002) "El crecimiento urbano de las ciudades intermedias del Nordeste Argentino en el contexto de las transformaciones regionales”, en Cuaderno Urbano $\mathrm{N}^{\circ} 3$, Nobuko, Corrientes.

Bekinschtein E, Caride H, Gravano A (2000), "En busca de los mapas de la memoria urbana. Una experiencia para la ciudad de Buenos Aires”, en Medio Ambiente y Urbanización. Año 16, Julio, Instituto Internacional de Medio Ambiente y Desarrollo. América Latina, Bueno Aires.

Benjamin, W. (2001) Dialéctica en suspenso. Fragmentos sobre historia, Arcis, Santiago de Chile.

Borja, J. (2005), “Revolución y contrarrevolución en la ciudad global”, en: Revista bibliográfica de Geografía y Ciencias Sociales (Serie documental de Geo Crítica) Vol. X, n ${ }^{\circ}$ 578, 20. Abril. Universidad de Barcelona, Barcelona. Disponible en http://www.ub.es/geocrit

Britez, W. (2006), Implementación de Políticas Habitacionales sin componentes sociales. El análisis de un caso testigo. Tesis de maestría. Programa de Políticas Sociales. Universidad Nacional de Misiones, Posadas.

Buck Morss, S. (2003), Dialéctica de la mirada, La balsa de Medusa, Barcelona.

Bruner, J (1992), América Latina: cultura y modernidad, Siglo XXI, México. 
Castoriadis, C. (1993), La institución imaginaria de la sociedad, Vol. 1 y 2, Buenos Aires, Tusquets.

De Certau, M (2000), La invención de lo cotidiano, Universidad Iberoamericana, México.

Díaz Orueta, F. (2005), “Ciudad y Globalización. Hacia la constitución de nuevos espacios sociales”, en Avá. Revista de Antropología, N 8, Programa de Postgrado en Antropología Social UNaM, Posadas.

Fontana Zoppi, Mónica (1997), Cidadãos Modernos. Discurso e Representação Política, UNICAMP, Campinas.

Ídem (1998), “Cidade e discurso -paradoxos do real, do imaginário, do virtual”, en Revista Rua. N4, NUCREDI, Campinas SP.

Foucault, M. (1999), El orden del discurso, Fabula Tus Quest, Barcelona.

Gorelik, A. (2004), La grilla y el Parque. Espacio público y cultura urbana en Buenos Aires 1887-1936. Universidad Nacional de Quilmes, Bernal.

Ídem (2004), Miradas sobre Buenos Aires. Historia Cultural y crítica urbana. Siglo XXI, Buenos Aires.

Ídem (2002), “Cultura Urbana y pensamiento social en América Latina”, Presentación en el seminario del Centre of Latin American Studies, Cambridge.

Guimarães E. (2002), Semântica do acontecimento, Pontes, Campinas.

Harvey, D. (1998), La condición de la Postmodernidad. Investigación sobre los orígenes del cambio cultural, Amorrortu, Buenos Aires.

Ídem (2007), Espacios del Capital, Akal, Madrid.

Lefebvre, H. (1972), La revolución urbana, Alianza, Madrid.

Licnerski J (2008), “Las grandes intervenciones urbanas como espacio de Centralidad”, I Congreso de Urbanismo y Ordenación del Territorio, Colegio de Ingenieros de Caminos, canales y puertos, Bilbao.

Maidana, E \& Millán M (2009), “Resonancias mediáticas de transformaciones urbanas en Posadas, Misiones”, en Cuaderno Urbano Espacio, Cultura y Sociedad N8, Nobuko/EUDENE, Buenos Aires.

Maingueneau, D. (2004), Le discours littéraire, Armand Colin, París.

Ídem (2003), Los términos clave del análisis del discurso, Nueva Visión, Buenos Aires. 
Ídem (1996), Novas tendências em análise do discurso, Pontes, Campinas.

Millán, M (2009) Posadas de papel. La costa y el discurso de lo urbano, Tesis de Maestría en Semiótica Discursiva, Programa de Semiótica, Universidad Nacional de Misiones, Posadas.

Motto, Carlos (2005), "Enemigos urbanos. La construcción de identidades amenazantes y nuevas políticas urbanas y sociales”, en Rozé, Murillo y Nuñez (comp.) Nuevas identidades urbanas en América Latina, Espacio, Buenos Aires.

Lins Ribeiro, G. (1999), La Represa de Yacyretá. Capitalismo transnacional y política hidroenergética en la Argentina, Editorial Universitaria de Misiones, Posadas.

Orlandi P., E. (2001), “Tralhas e trocos: o flagrante urbano”, en AA.VV. Cidade Atravessada, Pontes Campinas.

Pêcheux, M. (1995), Semântica e Discurso. Uma crítica a afirmação do obvio, UNICAMP, Campinas.

Talesnik, D.; Gutierrez, A. (2002), “Transformaciones de frentes de agua: la forma urbana como producto estándar”, en Eure (Santiago) Vol. 28, $\mathrm{N}^{\circ}$ 84. Septiembre, Pontificia Universidad Católica de Chile, Santiago de Chile.

Verón, E. (1996), La semiosis social. Fragmentos de una teoría de la discursividad, Gedisa, Barcelona.

Recibido: 01.10 .2010

Aceptado: 17.11.2010 